\title{
A systems biology approach to understand the pathophysiological mechanisms of cardiac pathological hypertrophy associated with rosiglitazone
}

Lars Verschuren ${ }^{1 *}$, Peter Y Wielinga ${ }^{2}$, Thomas Kelder ${ }^{1}$, Marijana Radonjic ${ }^{1}$, Kanita Salic ${ }^{2}$, Robert Kleemann ${ }^{2}$, Ben van Ommen ${ }^{1}$ and Teake Kooistra ${ }^{2}$

\begin{abstract}
Background: Cardiac pathological hypertrophy is associated with a significantly increased risk of coronary heart disease and has been observed in diabetic patients treated with rosiglitazone whereas most published studies do not suggest a similar increase in risk of cardiovascular events in pioglitazone-treated diabetic subjects. This study sought to understand the pathophysiological and molecular mechanisms underlying the disparate cardiovascular effects of rosiglitazone and pioglitazone and yield knowledge as to the causative nature of rosiglitazone-associated cardiac hypertrophy.
\end{abstract}

Methods: We used a high-fat diet-induced pre-diabetic mouse model to allow bioinformatics analysis of the transcriptome of the heart of mice treated with rosiglitazone or pioglitazone.

Results: Our data show that rosiglitazone and pioglitazone both markedly improved systemic markers for glucose homeostasis, fasting plasma glucose and insulin, and the urinary excretion of albumin. Only rosiglitazone, but not pioglitazone, tended to increase atherosclerosis and induced pathological cardiac hypertrophy, based on a significant increase in heart weight and increased expression of the validated markers, ANP and BNP. Functional enrichment analysis of the rosiglitazone-specific cardiac gene expression suggests that a shift in cardiac energy metabolism, in particular decreased fatty acid oxidation toward increased glucose utilization as indicated by down regulation of relevant PPARa and PGCla target genes. This underlies the rosiglitazone-associated pathological hypertrophic cardiac phenotype in the current study.

Conclusion: Application of a systems biology approach uncovered a shift in energy metabolism by rosiglitazone that may impact cardiac pathological hypertrophy.

\section{Background}

Type 2 diabetes mellitus (T2DM) is a strong independent risk factor for premature death and disability from heart failure [1]. Managing T2DM and related heart failure is an ongoing concern and adequate treatment of T2DM remains an important issue. Thiazolidinediones (TZDs) are a class of drugs that initially showed great promise as oral therapy for T2DM. The TZDs,

\footnotetext{
* Correspondence: Lars.Verschuren@tno.nl

${ }^{1}$ TNO, Department Microbiology and Systems Biology, P.O. Box 360, 3704 AJ Zeist, The Netherlands

Full list of author information is available at the end of the article
}

rosiglitazone and pioglitazone were widely used as hypoglycemic drugs in patients with T2DM, but due to a relatively high risk of adverse cardiac effects, specifically the use of rosiglitazone was banned in Europe in 2010 [2], whereas its use is restricted by the US Food and Drug Administration [3].

Despite their chemical and mechanistic similarities, there are large cohort studies suggesting that rosiglitazone causes heart failure to a greater extent than pioglitazone, yet provides no additional therapeutic benefit $[2,4,5]$. Questions as to how rosiglitazone may be leading to a relatively higher cardiovascular risk still remain

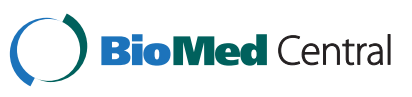


largely unanswered. Insight into the regulatory mechanisms underlying the disparate cardiovascular effects of rosiglitazone and pioglitazone may have translational implications and yield knowledge as to the causative nature of TZD-associated cardiac events in man [6].

Rosiglitazone and pioglitazone are thought to exert their primary therapeutic effects through binding to the peroxisome proliferator-activated receptor gamma (PPAR $\gamma$ ), thereby increasing sensitivity to insulin and producing better glycemic control [7]. Although PPAR is most abundantly expressed in adipose tissue, it is widely expressed throughout the body [8], including the liver, skeletal muscle and, to a lesser extent, in the heart. There is increasing evidence that activation of PPAR $\gamma$ by TZDs could alter the transcription of hundreds of genes, only part of which contribute to glycemic control. It is conceivable that some of the other altered gene transcription cascades may lead to the development of cardiovascular complications. In addition, PPAR $\gamma$-independent actions of TZDs have been suggested as a result of drug binding to cellular proteins different from PPARY [4]. In this respect it might be significant that rosiglitazone-induced myocardial hypertrophy, an early hallmark and important risk factor for the development of heart failure [9], still occurs in cardiomyocyte-specific PPAR $\gamma$ knock-out mice [10].

In the present study we have used a systems biology approach for assessing similarities and differences between rosiglitazone and pioglitazone in gene expression profiles in the heart of a mouse model that mimics several of the characteristics of diabetes as observed in humans treated with rosiglitazone or pioglitazone. Bioinformatic analysis of expression profiles was used to identify regulatory pathways and upstream regulators that are influenced by the two TZD treatments. Similarities in expression patterns between the two drugs may reveal unknown mechanisms of action in addition to PPAR $\gamma$ binding, and possible sources of shared effects. Conversely, differences may reveal different regulatory events leading to the increased cardiovascular risk that may be unique to a specific glitazone. From the current study several findings emerged that provide insights into differential effects of rosiglitazone and pioglitazone within the cardiovascular system, including implications for compounding drug efficacy and cardiotoxicity.

\section{Methods}

\section{Animals}

The study was approved by the animal Ethics Committee of TNO, the Netherlands, and animal handling was performed according to the European directive on Laboratory Animals (86/609/EEC). Male LDLr deficient mice were bred in TNO facilities and housed in wire- topped Macrolon cages with a layer of sawdust as bedding, and diets and water were provided ad libitum.

\section{Study design and diets}

The current study is part of a larger study, the design of which has been described in detail elsewhere [11]. In short, to induce characteristics of pre-diabetes, male LDLr deficient mice $(n=33)$ received Western type High Fat diet containing 24\% (w/w) lard fat (Research diets D12541, USA), further referred to as High-Fat (HF), diet for 9 weeks. Then, mice were subdivided into three experimental groups and matched for plasma cholesterol and body weight $(t=0)$. One group ( $n=15$ mice, control) continued the HF-diet treatment, while the other two groups were fed an HF-diet containing rosiglitazone $(0.01 \% \mathrm{w} / \mathrm{w}$; Avandia, GSK) or pioglitazone $(0.01 \% \mathrm{w} / \mathrm{w}$; Actos, Takeda) for an additional 7 weeks. The daily doses of rosiglitazone and pioglitazone are $5.6 \mathrm{mg} / \mathrm{kg}$ body weight/day and $7.2 \mathrm{mg} / \mathrm{kg}$ body weight, respectively. In parallel to these HF-diet groups a separate control group was kept on chow for the duration of the experiment and served as a reference control for aging. Throughout the experiment all experimental diets were well tolerated and mice in the various treatment groups consumed comparable amounts of calories.

\section{Analysis of plasma glucose and insulin, and urinary albumin levels}

Plasma was obtained via tail vein bleeding after 5 hours of fasting. Plasma glucose was quantified by the glucose hexokinase method (Instruchemie, Delfzijl, The Netherlands) and plasma insulin by ELISA (Ultrasensitive mouse insulin ELISA, Mercodia, Uppsala, Sweden). To assess glomerular barrier function, urinary albumin (Exocell Inc. Philadelphia, PA, USA) and creatinine concentrations were determined (Bethyl Laboratories Inc. Montgomery, TX, USA).

\section{Atherosclerotic lesion analysis}

At the end of the study, mice were euthanized to collect hearts and aortas. Hearts were weighted and divided in two parts. The apex of the heart was snap-frozen in liquid nitrogen and stored at $-80^{\circ} \mathrm{C}$. The upper part was fixed in formalin and embedded into paraffin to prepare serial cross sections (5 $\mu \mathrm{m}$-thick) throughout the entire aortic root area for histological analysis [12]. Cross-sections were stained with hematoxylin-phloxine-saffron (HPS) and atherosclerosis was analysed blindly in 4 cross-sections of each specimen (at intervals of $40 \mu \mathrm{m}$ ). An Olympus BX51 microscope and Cell^D software (Olympus, Zoeterwoude, The Netherlands) were used for morphometric computerassisted analysis of lesion number and area.

\section{Nucleic acid extraction and microarray analysis}

Nuclear acid extraction was performed as described previously in detail [13]. Briefly, total RNA was extracted from 
individual hearts $(\mathrm{n}=5-6$ hearts per experimental group, 16 samples in total, with normalized glucose levels at $<13 \mathrm{mM}$ ) using glass beads and RNAzol (Campro Scientific, Veenendaal, The Netherlands). RNA integrity was examined using the RNA 6000 Nano Lab-on-a-Chip kit and a bioanalyzer 2100 (Agilent Technologies, Amstelveen, The Netherlands). The Illumina $^{\oplus}$ TotalPrep $^{\text {тм }}$ RNA Amplification Kit (Ambion, art. No.AM-IL1791) was used to synthesize biotin labeled cRNA starting with $500 \mathrm{ng}$ total RNA. The concentration of the labeled cRNA was measured using the Nanodrop spectrophotometer. The amount of biotinylated cRNA which was hybridized onto the MouseRef-8 Expression BeadChip was 750 ng. Illumina's Genomestudio v1.1.1 software with the default settings advised by Illumina was used for Gene Expression analysis. All the quality control data of this BeadChip were within specifications of the microarray service provider (Service XS, Leiden, the Netherlands).

\section{Microarray data analysis}

The probe-level background subtracted expression values were used as input for lumi package [14] of the R/Bioconductor (http://www.bioconductor.org; http://www.r-project. org) to perform quality control and a quantile normalization. Unexpressed probes ( $p>0.01$ in all experiments) were removed from further analysis, and 15725 probes remained in the analysis. Differentially expressed probes were identified using the limma package of R/Bioconductor [15]. The calculated P-values <0.01 were used as threshold for significance in cardiac tissue. Selected differentially expressed probes (DEPs) were used as an input for pathway analysis through Ingenuity Pathway Analysis suite (www.ingenuity. com, accessed 2013).

Upstream regulator analysis was performed using the Ingenuity Pathway Analysis (IPA) software. This analysis determines the activation state of transcription factors based on the observed differential gene expression. This results in an overlap p-value and activation z-score for each transcription factor in the IPA knowledgebase. The overlap p-value indicates the significance of the overlap between the known target genes of a transcription factor and the differentially expressed genes measured in an experiment. The activation z-score indicates activation (positive $\mathrm{z}$-score) or inhibition (negative z-score) of a particular transcription factor. An activation $\mathrm{z}$-score $<-2$ or $>2$ indicates significant activation or inhibition of a pathway or process.

\section{cDNA synthesis and quantitative real-time polymerase chain reaction}

cDNA was synthesized from heart tissue RNA from mice in the HF + Rosi and HF + Pio groups with similar, i.e. normalized glucose levels. One microgram of total RNA was used for the high capacity RNA to cDNA kit
(4387406, Applied Biosystems). Real time PCR was performed in triplicate on a Fast 7500 using the TaqMan gene expression assays (Applied Biosystems). Specific probes were applied to detect transcripts for B-type natriuretic peptide (Bnp;Mm01255770_g1 ) and A-type natriuretic peptide (Anp;Mm01255747_g1). The probes solute carrier family 27 (fatty acid transporter), member 1 (Slc27a1,Fatp; Mm00449511_M1), uncoupling protein 3 (Ucp3; Mm00494077_M1), Acyl-CoA dehydrogenase, very long chain (Acadvl Mm00444293_M1), and carnitine palmitoyltransferase 1b (Cpt1b; Mm00487200_M1) were applied to validate microarray results. All signals were compared to glyceraldehyde 3-phosphate dehydrogenase (Gapdh;4308313), hypoxanthine-guanine phosphoribosyltransferase (Hprt;Mm00446968_m1) and peptidylprolyl isomerase F (PpifMm00506384_m1) as housekeeping genes.

\section{Statistics}

All efficacy data are presented as mean \pm standard deviation (SD). Data were analyzed using One-Way analysis of variance (ANOVA) and least significant difference (LSD) post hoc test unless stated otherwise. In all tests performed, the null hypothesis was rejected at the level of 5\% probability $(\alpha=0.05)$.

\section{Results}

\section{Metabolic parameters}

LDLr-/- mice fed an HF-diet over a 16-week period showed a significantly higher increase in body weight $(15.8 \pm 4.6 \mathrm{~g})$ relative to mice on standard chow $(3.2 \pm$ 1.6 g; $\mathrm{P}<0.001)$. The body weight gains of mice fed $\mathrm{HF}+$ Rosiglitazone (HF + Rosi) or HF + Pioglitazone ( $\mathrm{HF}+\mathrm{Pio})$ tended to be even higher than those of HF fed mice $(+14 \%$ and $+10 \%$, respectively; not statistically significant).

HF-diet significantly increased plasma fasting glucose $(15.0 \pm 1.9 \mathrm{mM} ; \mathrm{P}<0.001$; Figure $1 \mathrm{~A})$ compared to chow diet $(11.3 \pm 1.6 \mathrm{mM})$. HF + Rosi and $\mathrm{HF}+$ Pio treatment significantly reduced fasting glucose levels to $10.6 \pm 0.7$ $\mathrm{mM}(\mathrm{P}<0.01)$ and $12.2 \pm 2.1 \mathrm{mM}(\mathrm{P}<0.01)$, respectively. Fasting plasma insulin levels significantly increased with HF-diet to $4.3 \pm 3.3 \mathrm{ng} / \mathrm{ml}$ vs. $0.7 \pm 0.5 \mathrm{ng} / \mathrm{ml}$ with chow $\operatorname{diet}(\mathrm{P}<0.001$; Figure $1 \mathrm{~B}) . \mathrm{HF}+\operatorname{Rosi}(1.4 \pm 0.6 \mathrm{ng} / \mathrm{ml} ; \mathrm{P}<$ $0.01)$ and $\mathrm{HF}+\mathrm{Pio}(2.7 \pm 1.8 \mathrm{ng} / \mathrm{ml} ; \mathrm{P}=0.09)$ treatment reduced fasting insulin levels. Urinary albumin/creatinine ratio, an indication for microalbuminuria, showed a 2.8fold increase $(186 \pm 29 \mu \mathrm{g} / \mathrm{mg} ; \mathrm{P}<0.05$; Figure $1 \mathrm{C})$ with HF-diet compared to chow diet $(65 \pm 19 \mu \mathrm{g} / \mathrm{mg})$. Both $\mathrm{HF}+$ Rosi $(116 \pm 39 \mu \mathrm{g} / \mathrm{mg} ; \mathrm{P}<0.05)$ and $\mathrm{HF}+\mathrm{Pio}(143 \pm$ $25 \mu \mathrm{g} / \mathrm{mg} ; \mathrm{P}<0.05)$ significantly reduced the HF-dietinduced increase in albumin/creatinine ratio. In all, these data demonstrate that both $\mathrm{HF}+$ Rosi and $\mathrm{HF}+$ Pio improve metabolic parameters efficiently. 

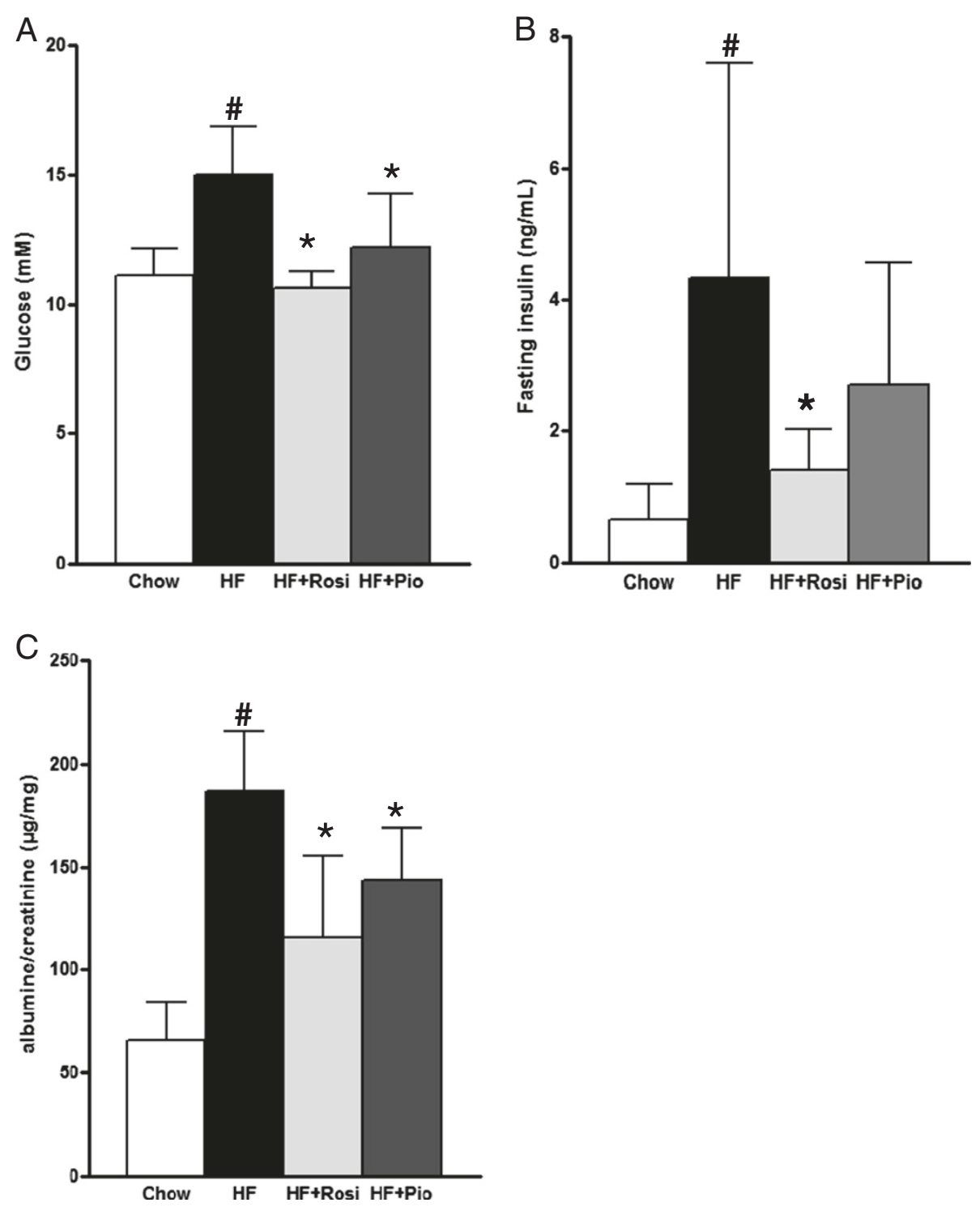

Figure 1 Effect of drug treatment on metabolic parameters in LDLr-/- mice fed a chow diet or an HF-diet supplemented with rosiglitazone (HF + Rosi) or pioglitazone (HF + Pio). Fasting plasma levels of glucose (A) and insulin (B), and albumin/creatinin ratio in urine (C). Values are mean \pm SD. \# indicates statistical significance $P<0.05$ compared to chow, ${ }^{*}$ indicates statistical significance $P<0.05$ compared to HF-diet.

\section{Cardiac parameters}

HF-diet increased heart weight only slightly $(167 \pm 30 \mathrm{mg})$ compared to chow (151 $\pm 15 \mathrm{mg}$; not significant). Treatment with rosiglitazone significantly increased heart weight relative to HF $(211 \pm 29 \mathrm{mg}$; $<0.05$; Figure $2 \mathrm{~A})$. Also, the heart-to-body weight ratio $(\mathrm{HW} / \mathrm{BW})$ of $\mathrm{HF}+$ Rosi was increased compared with HF-diet $(0.48 \% \pm$ $0.06 \%$ vs. $0.39 \% \pm 0.06 \%$; $<<0.05)$. In contrast, pioglitazone did not affect heart weight (172 $\pm 34 \mathrm{mg})$ or HW/ $\mathrm{BW}$ ratio $(0.40 \% \pm 0.06 \%)$ compared with HF. The increased heart weight in the HF + Rosi group was accompanied by an upregulation of the fetal/stress genes B-type natriuretic peptide (Bnp) $(2.43 \pm 0.33$; $\mathrm{P}<0.001$; Figure $2 \mathrm{~B})$ and atrial natriuretic peptide (Anp) (1.62 \pm
$0.44 ; \mathrm{P}<0.01$; Figure $2 \mathrm{C})$, relative to the $\mathrm{HF}$ group (Bnp, $1.0 \pm 0.14 ;$ Anp, $1.0 \pm 0.14$ ). Augmented expression of Bnp and Anp indicates pathological cardiac growth of the heart, which is an important and independent risk factor for cardiovascular diseases. Notably, Bnp $(1.19 \pm 0.41)$ and $A n p(0.88 \pm 0.36)$ transcript levels were not significantly altered with pioglitazone. Another common cause of cardiovascular disease is the development of atherosclerosis. Histological analysis of the aortic root showed that 16 weeks of HF-diet treatment alone mildly increased atherosclerosis development in LDLrdeficient mice $\left(23,800 \pm 4,460 \mu^{2}\right)$ compared with chowfed mice $\left(4,300 \pm 850 \mu \mathrm{m}^{2} ; \mathrm{P}<0.01\right)$. Rosiglitazone treatment tended to further increase total atherosclerosis area 


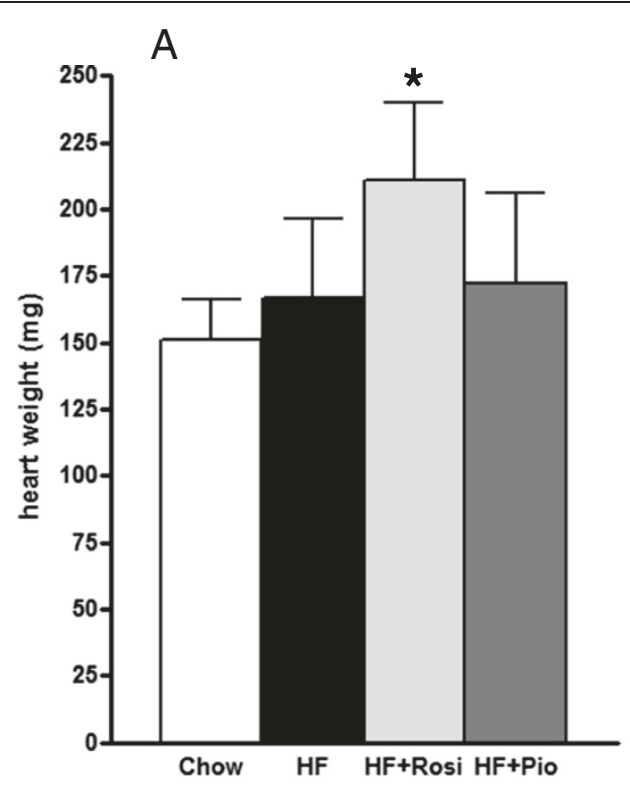

B

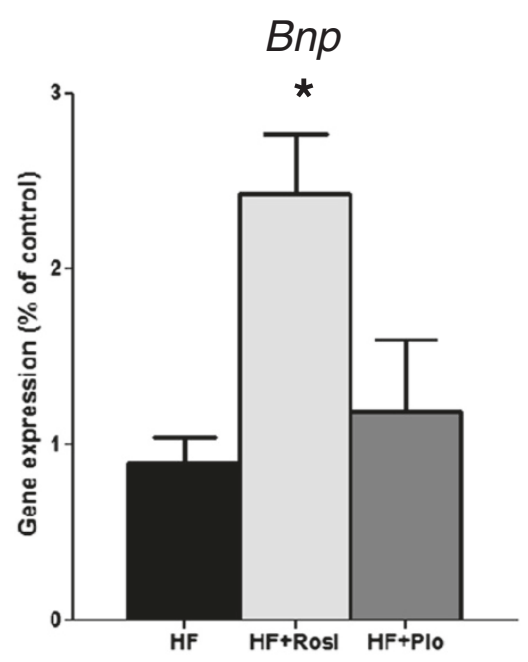

C
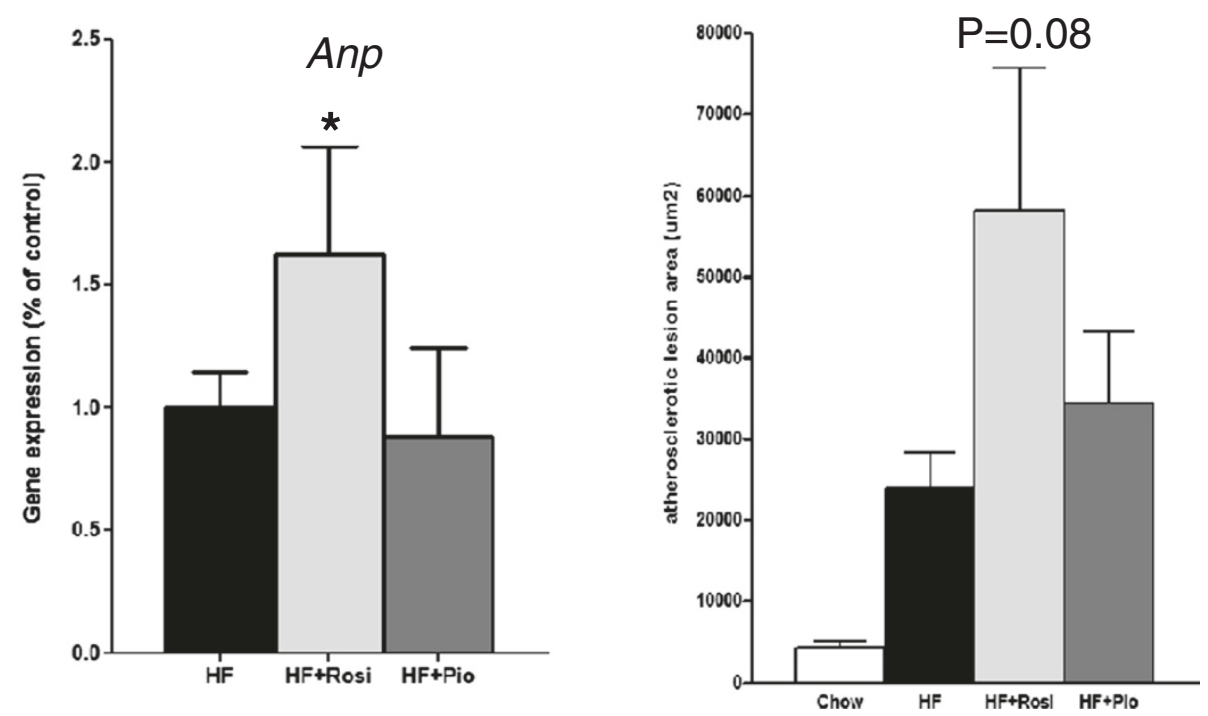

Figure 2 Effect of drug treatment on cardiac parameters of LDLr-/- mice. Heart weight (A), gene expression of cardiac stress marker Bnp (B), and Anp (C) assessed by RT-PCR, and quantitative analysis of atherosclerotic lesions in the aortic root area (D). Values are mean \pm SEM. \# indicates statistical significance $\mathrm{P}<0.05$ compared to chow, ${ }^{*}$ indicates statistical significance $\mathrm{P}<0.05$ compared to HF-diet.

in the aortic root $\left(58200 \pm 17470 \mu \mathrm{m}^{2}\right.$; Figure 2D; $\left.\mathrm{P}=0.08\right)$, while HF + Pio showed no significant differences $(34300 \pm$ $8830 \mu \mathrm{m}^{2}$ ). The question then arises what mechanistic processes could underlie these cardiac adverse effects of rosiglitazone. To address this question a genomewide gene expression analysis of selected heart tissue samples was carried out.

\section{Genome-wide transcriptome analysis}

To elucidate which gene regulatory processes are modulated in the hearts of HF + Rosi and HF + Rio treated mice, transcriptome analysis of heart tissue was performed. Of note, heart tissue was used from mice that showed normalized plasma glucose levels (viz. below $13 \mathrm{mM}$ ) upon rosiglitazone or pioglitazone treatment (Figure 3A). Genes that were differentially expressed in the HF + Rosi (Additional file 1: Table S1) and HF + Pio (Additional file 2: Table S2) treatment groups relative to the HFgroup were used for analysis of biological processes. The majority of the affected genes were modulated by rosiglitazone (700 genes compared to 345 genes with pioglitazone), and 76 genes were affected by both compounds (Venn-diagram; Figure 3B). Notably, only 39 genes of the genes affected by rosiglitazone are controlled by 

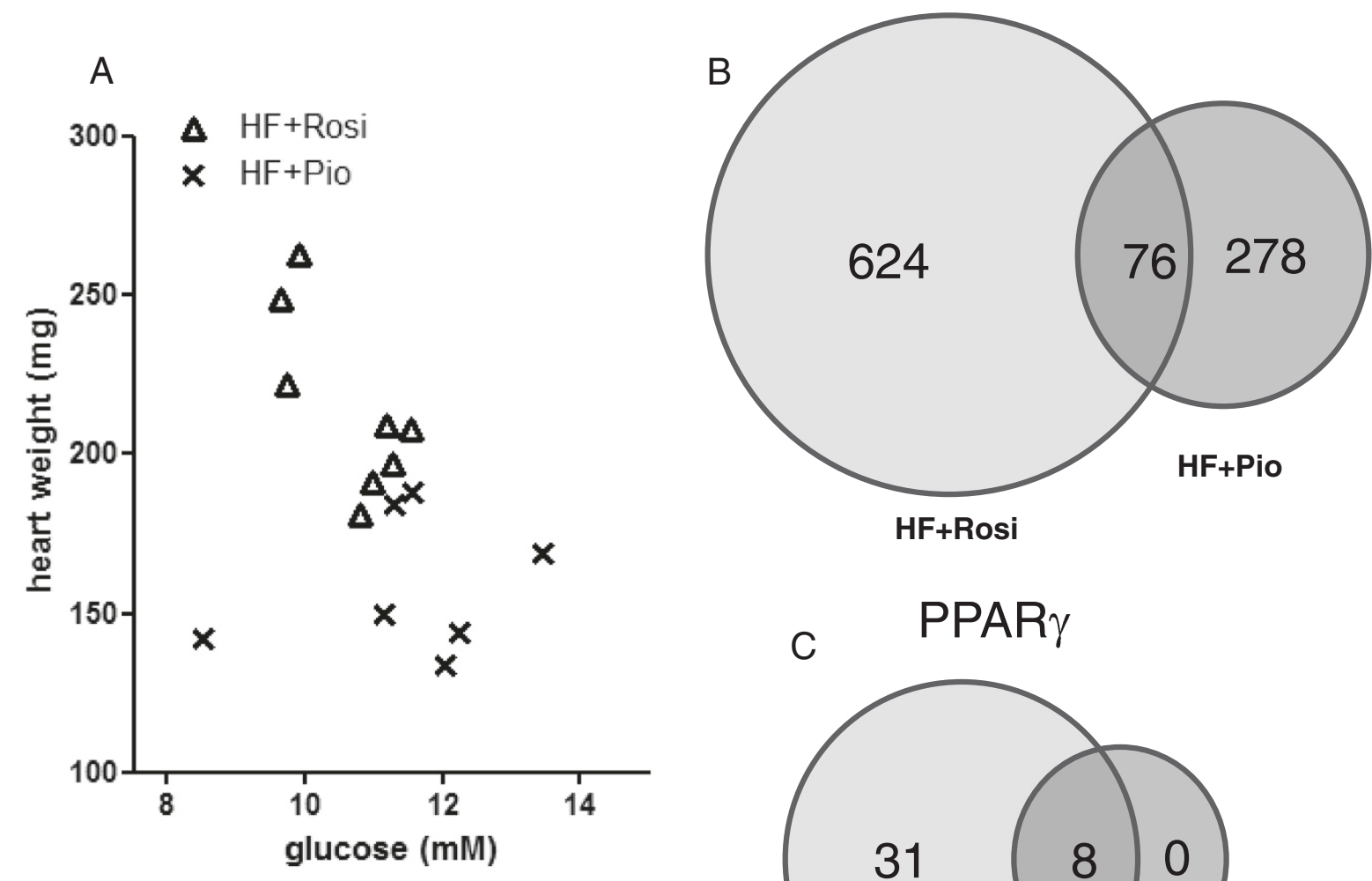

HF+Rosi

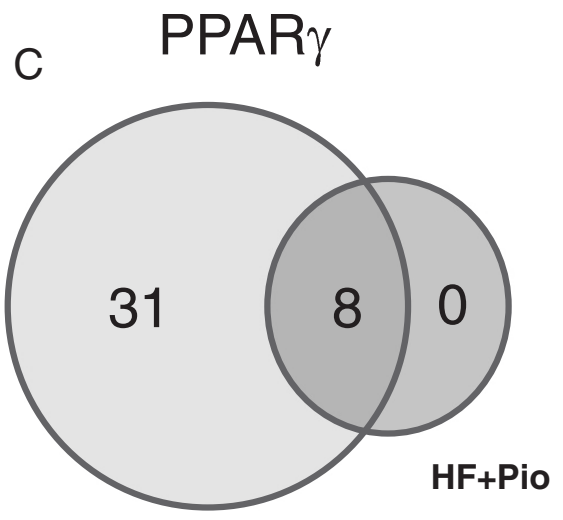

$\mathrm{D}$

HF+Rosi

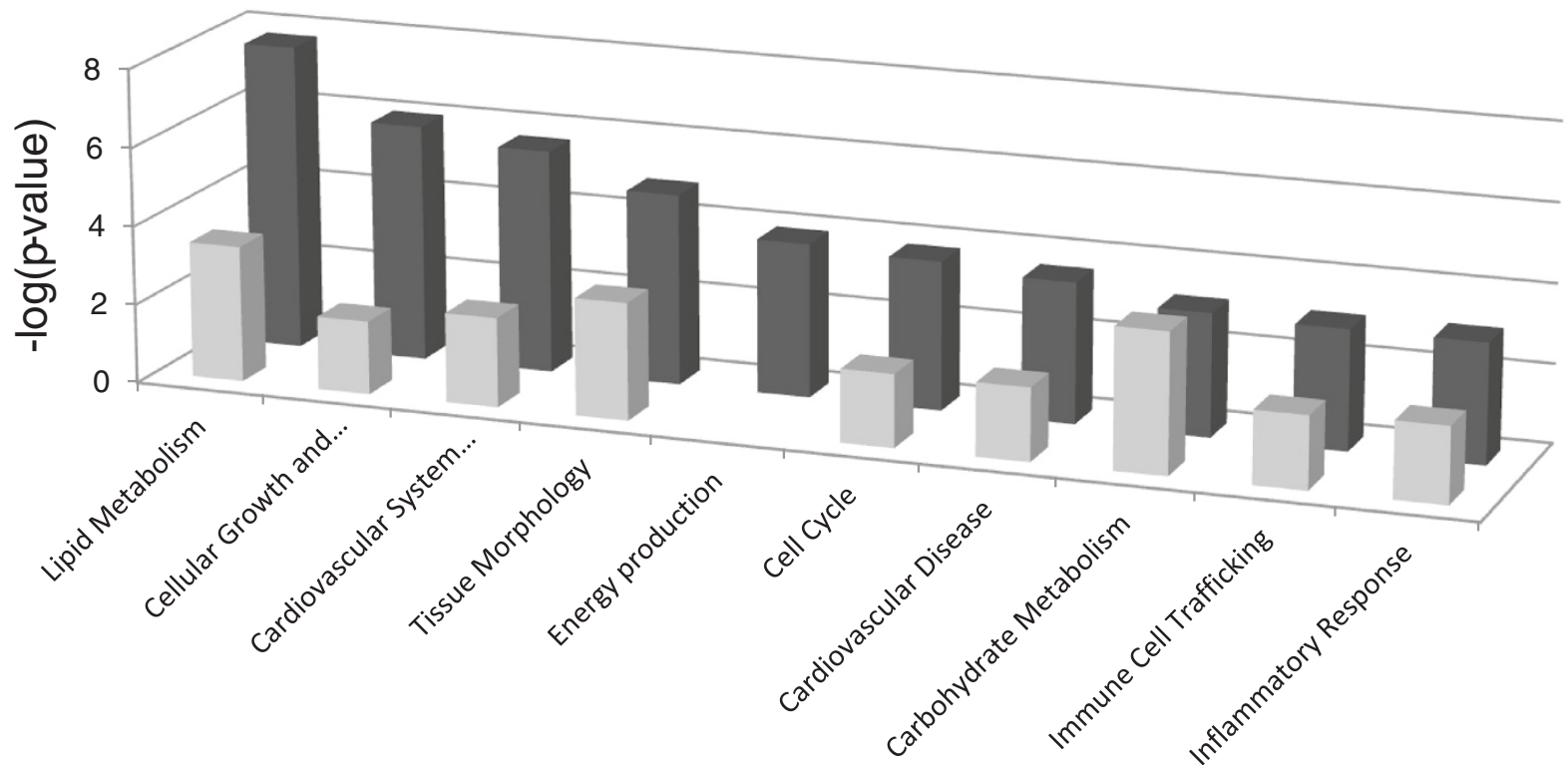

Figure 3 Cardiac transcriptome analysis. Relationship between fasting plasma glucose concentration and heart weight (A), Venn-diagrams showing overlap in the total number of differentially expressed genes (B) and PPARy target genes (C) in cardiac tissue in HF + Rosi and HF + Pio groups relative to HF-diet control group ( $P<0.01$ ). Graphical representation (D) of significantly enriched Biological Processes in HF + Rosi and HF + Pio treatment groups relative to HF-diet control group. Bars display a selection of significantly enriched biological processes (-log10 (p-value)) modulated by HF + Rosi (dark bars) or HF + Pio (light bars). 
PPARY and 8 of these were also affected by pioglitazone (Figure 3C). Together this shows that treatment with rosiglitazone, and to a lesser extent pioglitazone, is accompanied by substantial gene expression changes in the heart, but most of these changes are not direct related to PPAR $\gamma$.

To get insight into potential changes of biological processes geneset enrichment analysis was performed. Sixty-seven (67) processes were significantly enriched by rosiglitazone and 49 processes by pioglitazone (Threshold p-value 0.001; Additional file 3: Table S3). The process "Carbohydrate metabolism" was affected by both drugs and to a comparable extent. All other processes including "Lipid Metabolism" and "Inflammatory Response" were affected by rosiglitazone to greater extent than by pioglitazone (Figure 3D). Of note, the process "Energy Production" was affected by rosiglitazone only.

To further delineate the molecular processes that could underlie the adverse cardiac effects of rosiglitazone, we evaluated the rosiglitazone-specific genes of the Venn-diagram. In silico prediction of transcription factor activity based on the expression changes of known target genes revealed reduced activity of PPAR $\alpha$ ( $p$-value 3.4E-10; z-score -3.1) and PGC1 $\alpha$ (p-value 1.1E-03; $\mathrm{z}$-score -2.1) upon rosiglitazone treatment and an effect on target genes in the heart, including UCP3, FATP1, CPT-1, and ACADVL (Additional file 4: Table S4). The specific findings on the target genes from the transcriptome analysis are validated using RT-PCR method (Figure 4A-D). Functional geneset enrichment analysis of the dataset shows that these rosiglitazone-specific effects, involving PPAR $\alpha$ and/or PGC1 $\alpha$-controlled genes, do at least partly explain the typical effects on the biological processes: Lipid Metabolism, Fatty Acid Metabolism and Energy Production (Venn diagrams; Figure 5A and B). Overall the effects of rosiglitazone on PPAR $\alpha$ and PGC1 $\alpha$ regulated genes indicate a strong down regulation of genes involved in Lipid Metabolism (Figure 5C) and Energy Production (Figure 5D) in the heart which might contribute to the observed pathological hypertrophy because such effects were not observed with pioglitazone.

\section{Discussion}

The discrepancy in cardiovascular risk between patients taking rosiglitazone or pioglitazone and lack of insight into the underlying causes elicited the present study in mice $[16,17]$. Mouse heart tissue was used, since this allowed a comprehensive analysis of similarities and differences between rosiglitazone and pioglitazone. Bioinformatic analysis of the gene expression data identified regulatory pathways and upstream regulators that are specifically influenced by rosiglitazone.

In a high-fat diet-inducible model of combined hyperglycemia and cardiovascular disease we found that rosiglitazone and pioglitazone are effective glucose lowering drugs which markedly improved systemic markers of glucose homeostasis, fasting plasma glucose and insulin, and the urinary excretion of albumin. These findings are in line with observations made in humans [18,19] and other rodent models [20,21]. Importantly, only rosiglitazone treatment caused cardiac hypertrophy, defined as a significant increase in heart weight, and tended to increase atherosclerosis in the aortic root area. To our knowledge the disparate capacity of rosiglitazone and pioglitazone to induce cardiac hypertrophy was never studied before in a diet-induced mouse model. In general, two forms of cardiac hypertrophy can be distinguished, physiological and pathological hypertrophy. The latter is a significant independent risk factor for cardiovascular mortality and morbidity ([22], and references therein). Our study demonstrate that validated markers for pathological cardiac hypertrophy, ANP and BNP [23], were elevated by rosiglitazone but not by pioglitazone. This demonstrates that only rosiglitazone induced pathological cardiac hypertrophy in these mice within the study period of 7 weeks. Consistent with our observation in mice, rosiglitazone treatment also increased BNP plasma levels in T2DM patients without previous signs of cardiovascular disease [24], while pioglitazone did not have an effect on BNP levels [25].

Microarray technology is a powerful technique to analyze the effect of interventions on thousands of genes and across pathways [13]. Transcriptome analysis of the heart tissue revealed that, under conditions at which rosiglitazone and pioglitazone showed comparable hypoglycemic effects, 624 genes were significantly and differently altered by rosiglitazone. Only 31 of these are reportedly controlled by PPAR $\gamma$. Furthermore, our analysis demonstrates that 354 genes are affected by pioglitazone, only 8 genes of which are target of PPAR $\gamma$ and all are in common with rosiglitazone. This implies, that in case the pathological cardiac hypertrophy is induced through a PPAR $\gamma$-dependent mechanism, it could be caused by 31 rosiglitazone-modulated genes. However, the role of PPARY in the development of pathological cardiac hypertrophy and in mediating the effect of rosiglitazone thereupon is not entirely clear yet. Several studies suggest that PPAR $\gamma$ is protective, as mice lacking PPAR $\gamma$ in the heart developed cardiac hypertrophy and dysfunction [26,27] and treatment with a PPAR $\gamma$ agonist reduced cardiac remodeling and fibrosis in a rat model of hypertension [27]. Yet, cardiac-specific over-expression of PPARy in mice also resulted in cardiac dysfunction [28]. Another study demonstrated that transgenic mice with enhanced PPAR $\gamma$ activity developed concentric hypertrophy which progressed to dilated cardiomyopathy [29]. On the other hand, a study using cardiomyocytespecific PPAR $\gamma$ knock-out mice indicated that rosiglitazone can promote the development of myocardial hypertrophy in a PPAR $\gamma$-independent manner [10]. 


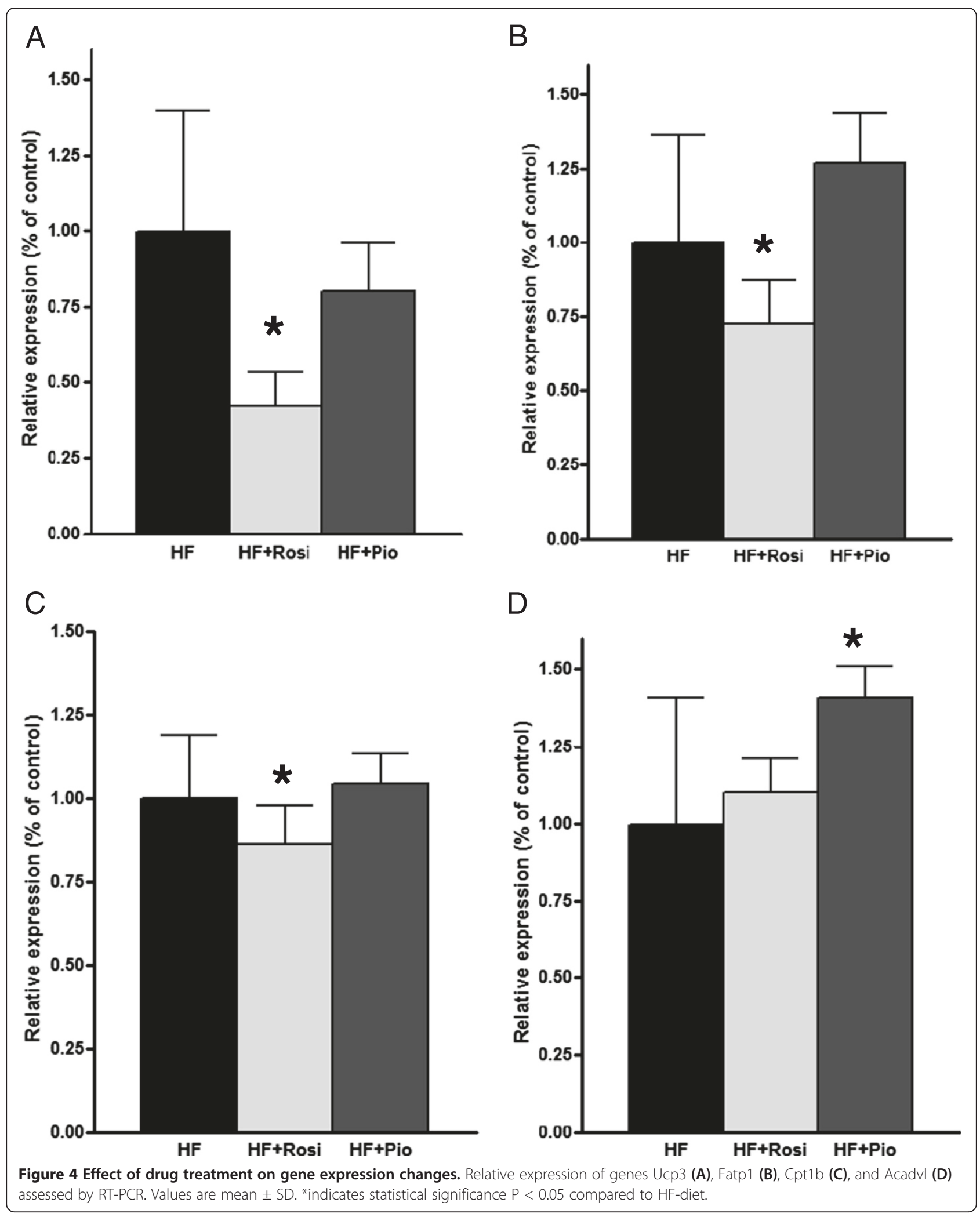

The heart relies on a constant high supply of energy, primarily met by the $\beta$-oxidation of fatty acids, to maintain the continuous contractile activity [30]. There is increasing evidence that a shift in cardiac energy metabolism towards decreased fatty acid oxidation and increased glucose utilization, can contribute to the development of 

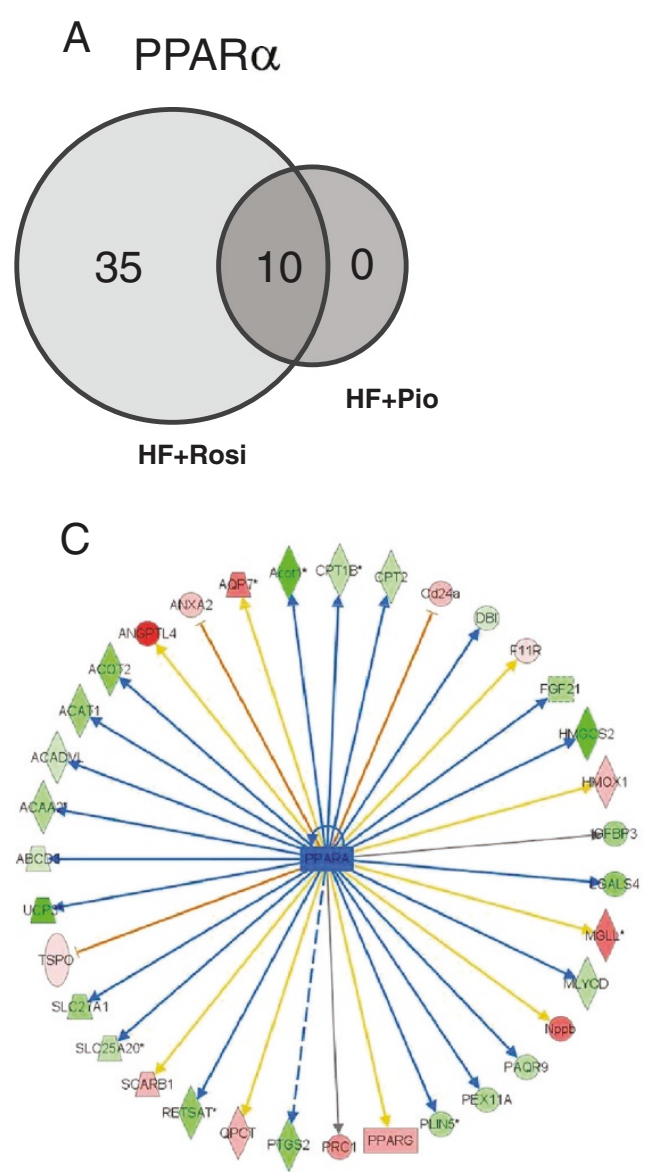
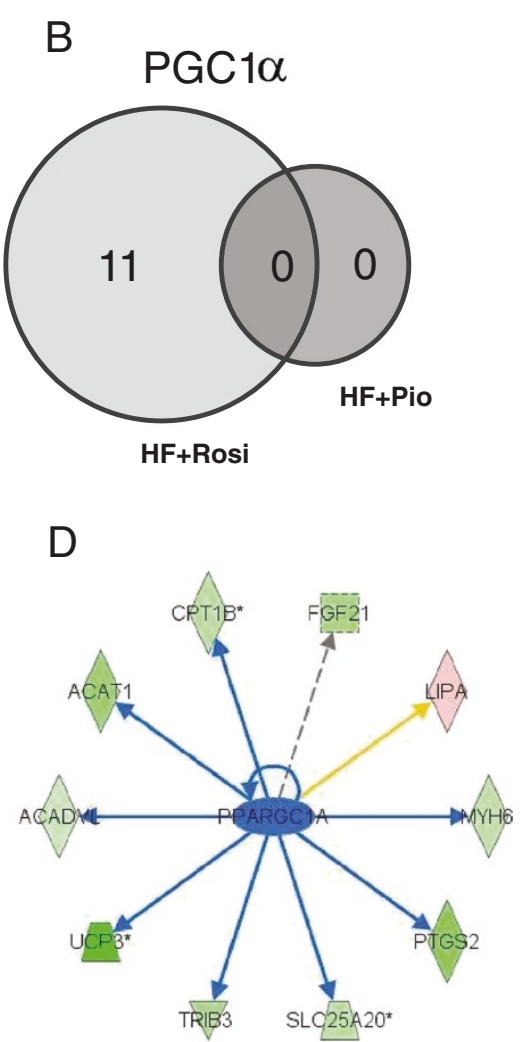

Figure 5 PPARa and PGC1a target gene regulation. Venn-diagrams displaying the number of target genes affected by nuclear transcription factor PPARa (A) and PGC1a (B). PPARa (C) and PGC1a (D) target genes that are significantly upregulated (red) or downregulated (green) by rosiglitazone relative to HF-diet control $(P<0.01)$.

pathological heart hypertrophy and failure [30]. Transcriptome analysis of the heart revealed that such a switch from fatty acid to glycolytic metabolism may also underlie the rosiglitazone-associated pathological hypertrophic cardiac phenotype in the current study. Rosiglitazone, but not pioglitazone, down regulated PPAR $\alpha$ and PGC1 $\alpha$ target genes. In PPAR $\alpha-/-$ mice, cardiac hypertrophy is induced [31], and also in mice lacking PGC-1 $\alpha$, cardiac dysfunction becomes evident [32]. Functional enrichment analysis of the genes specifically affected by rosiglitazone indicates that the down regulated genes are related to biological processes 'Lipid Metabolism' and 'Energy Production' and included CPT1, VLCAD, and LCAD. Inhibition of CPT1 in cardiac tissue has been demonstrated to induce cardiac hypertrophy [33,34]. Similarly, cardiac hypertrophy was found in mice deficient in VLCAD or LCAD [35]. Further evidence for a putative role of PPAR $\alpha$ in cardiac hypertrophy comes from studies on fibroblast growth factor 21 (FGF21), which is expressed in and released by cardiomyocytes through a PPAR $\alpha$ - dependent mechanism [36]. Deficiency of FGF21 in the heart was demonstrated to induce of cardiac hypertrophy markers and reduce fatty acid oxidation [37].

\section{Conclusion}

The mouse model of rosiglitazone-induced cardiac pathological hypertrophy combined with bioinformatics analysis of the transcriptome of the heart offers important insights into the pathophysiology of adverse cardiac hypertrophy. In particular, we uncovered a shift in cardiac energy metabolism from fatty acid oxidation toward increased glucose utilization and the roles of relevant PPAR $\alpha$ and PGC1 $\alpha$ target genes therein. These findings are also relevant for improving future drug efficacy void of cardiotoxicity.

\section{Additional files}

Additional file 1: Table S1. Differentially expressed genes in HF+Rosi treated group relative to HF-group.

Additional file 2: Table S2. Differentially expressed genes in HF+Pio treated group relative to HF-group. 
Additional file 3: Table S3. Biological processes significantly enriched in HF+ Rosi and HF+Pio relative to HF-group.

Additional file 4: Table S4. Target molecules that are regulated by $\mathrm{HF}+$ Rosi and are predicted to be regulated by PPARa and/or PGC1a.

\section{Competing interest}

The authors declare that they have no competing interests.

\section{Authors' contribution}

$\mathrm{LV}, \mathrm{BVO}$, TeKo and RK conceived and designed the experiments. PYW, KS performed the experiments. LV, MR, ThKe analyzed the data. LV, BvO and TeKo wrote the manuscript. All authors read and approved the final manuscript.

\section{Acknowledgement}

We thank Wim van Duyvenvoorde, Eric H. Offerman, and Karin Toet for their technical and analytical expertise. This study was sponsored by a TNO enabling technology program: "Enabling Technology Systems Biology" (ETSB). The funder had no role in study design, data collection and analysis, decision to publish, or preparation of the manuscript.

\section{Author details}

${ }^{1}$ TNO, Department Microbiology and Systems Biology, P.O. Box 360, 3704 AJ Zeist, The Netherlands. ${ }^{2} \mathrm{TNO}$, Department Metabolic Health Research, Leiden, The Netherlands.

Received: 5 November 2013 Accepted: 16 May 2014 Published: 17 June 2014

\section{References}

1. Khalaf Kl, Taegtmeyer H: After avandia: the use of antidiabetic drugs in patients with heart failure. Tex Heart Inst J 2012, 39(2):174-178.

2. Loke YK, Kwok CS, Singh S: Comparative cardiovascular effects of thiazolidinediones: systematic review and meta-analysis of observational studies. BMJ 2011, 342:d1309.

3. US FDA: Avandia (rosiglitazone): REMS - risk of cardiovascular events [online]. Available from URL: http://www.fda.gov/Safety/MedWatch/ SafetyInformation/SafetyAlertsforHumanMedicalProducts/ucm226994.htm [Accessed 2010 Dec 6].

4. Hoffmann BR, El-Mansy MF, Sem DS, Greene AS: Chemical proteomicsbased analysis of off-target binding profiles for rosiglitazone and pioglitazone: clues for assessing potential for cardiotoxicity. J Med Chem 2012, 55(19):8260-8271.

5. DREAM (Diabetes REduction Assessment with ramipril and rosiglitazone Medication) Trial Investigators, Gerstein HC, Yusuf S, Bosch J, Pogue J, Sheridan P, Dinccag N, Hanefeld M, Hoogwerf B, Laakso M, Mohan V, Shaw J, Zinman B, Holman RR: Effect of rosiglitazone on the frequency of diabetes in patients with impaired glucose tolerance or impaired fasting glucose: a randomised controlled trial. Lancet 2006, 368(9541):1096-1105.

6. Mikaelian I, Buness A, Hirkaler G, Fernandes R, Coluccio D, Geng W, Visalli T, Bachynsky MO, Berkofsky-Fessler W, Kanwal C, Hilton H, Nicklaus R, Hoflack JC, Dunn M, Sanders M, Giron M, Boyle BW, Singer T, Dick LS: Serum cardiac troponin I concentrations transiently increase in rats given rosiglitazone. Toxicol Lett 2011, 201(2):110-115.

7. Lehmann JM, Moore LB, Smith-Oliver TA, Wilkison WO, Willson TM, Kliewer SA: An antidiabetic thiazolidinedione is a high affinity ligand for peroxisome proliferator-activated receptor gamma (PPAR gamma). J Biol Chem 1995, 270(22):12953-12956.

8. Kung J, Henry RR: Thiazolidinedione safety. Expert Opin Drug Saf 2012, 11(4):565-579.

9. Creemers EE, Wilde AA, Pinto YM: Heart failure: advances through genomics. Nat Rev Genet 2011, 12(5):357-362.

10. Duan SZ, Ivashchenko CY, Russell MW, Milstone DS, Mortensen RM: Cardiomyocyte-specific knockout and agonist of peroxisome proliferator-activated receptor-gamma both induce cardiac hypertrophy in mice. Circ Res 2005, 97(4):372-379.

11. Radonjic M, Wielinga PY, Wopereis S, Kelder T, Goelela VS, Verschuren L, Toet $K$, van Duyvenvoorde W, van der Werff van der Vat B, Stroeve JH, Cnubben N, Kooistra T, van Ommen B, Kleemann R: Differential effects of drug interventions and dietary lifestyle in developing type 2 diabetes and complications: a systems biology analysis in LDLr-/- mice. PLOS One 2013, 8(2):e56122.

12. Verschuren L, Kleemann R, Offerman EH, Szalai AJ, Emeis SJ, Princen HM, Kooistra T: Effect of low dose atorvastatin versus diet-induced cholesterol lowering on atherosclerotic lesion progression and inflammation in apolipoprotein E3-Leiden transgenic mice. Arterioscler Thromb Vasc Bio 2005, 25(1):161-167.

13. Verschuren L, Radonjic M, Wielinga PY, Kelder T, Kooistra T, van Ommen B, Kleemann R: Systems biology analysis unravels the complementary action of combined rosuvastatin and ezetimibe therapy. Pharmacogenet Genomics 2012, 22(12):837-845.

14. Du P, Kibbe WA, Lin SM: lumi: a pipeline for processing Illumina microarray. Bioinformatics 2008, 24(13):1547-1548.

15. Smyth GK: Linear models and empirical bayes methods for assessing differential expression in microarray experiments. Stat Appl Genet Mol Biol 2004, 3: Article3.

16. Nissen SE, Wolski K: Effect of rosiglitazone on the risk of myocardial infarction and death from cardiovascular causes. N Engl J Med 2007 356(24):2457-2471.

17. Kaul S, Bolger AF, Herrington D, Giugliano RP, Eckel RH: American Heart Association, American College Of Cardiology Foundation: Thiazolidinedione drugs and cardiovascular risks: a science advisory from the American Heart Association and American College Of Cardiology Foundation. J Am Coll Cardiol 2010, 55(17):1885-1894

18. Lachin JM, Viberti G, Zinman B, Haffner SM, Aftring RP, Paul G, Kravitz BG, Herman WH, Holman RR, Kahn SE, ADOPT Study Group: Renal function in type 2 diabetes with rosiglitazone, metformin, and glyburide monotherapy. Clin J Am Soc Nephrol 2011, 6(5):1032-1040.

19. Home PD, Kahn SE, Jones NP, Noronha D, Beck-Nielsen H, Viberti G, ADOP Study Group: RECORD Steering Committee: Experience of malignancies with oral glucose-lowering drugs in the randomised controlled ADOPT (A Diabetes Outcome Progression Trial) and RECORD (Rosiglitazone Evaluated for Cardiovascular Outcomes and Regulation of Glycaemia in Diabetes) clinical trials. Diabetologia 2010, 53(9):1838-1845.

20. Kus V, Flachs P, Kuda O, Bardova K, Janovska P, Svobodova M, Jilkova ZM, Rossmeisl M, Wang-Sattler R, Yu Z, Illig T, Kopecky J: Unmasking differential effects of rosiglitazone and pioglitazone in the combination treatment with $\mathrm{n}-3$ fatty acids in mice fed a high-fat diet. PLoS One 2011, 6(11):e27126.

21. Ohga S, Shikata K, Yozai K, Okada S, Ogawa D, Usui H, Wada J, Shikata Y, Makino $\mathrm{H}$ : Thiazolidinedione ameliorates renal injury in experimental diabetic rats through anti-inflammatory effects mediated by inhibition of NF-kappaB activation. Am J Physiol Renal Physiol 2007, 292(4):F1141-F1150.

22. Bernardo BC, Weeks KL, Pretorius L, McMullen JR: Molecular distinction between physiological and pathological cardiac hypertrophy: experimental findings and therapeutic strategies. Pharmacol Ther 2010 128(1):191-227.

23. Grandi AM, Laurita E, Selva E, Piantanida E, Imperiale D, Giovanella L, Guast $L$, Venco A: Natriuretic peptides as markers of preclinical cardiac disease in obesity. Eur J Clin Invest 2004, 34(5):342-348.

24. Turkmen Kemal Y, Guvener Demirag N, Yildirir A, Atar A, Dogruk Unal A Biyiklioglu Z: Effects of rosiglitazone on plasma brain natriuretic peptide levels and myocardial performance index in patients with type 2 diabetes mellitus. Acta Diabeto/ 2007, 44(3):149-156.

25. Ogawa S, Takeuchi K, Ito S: Plasma BNP levels in the treatment of type 2 diabetes with pioglitazone. J Clin Endocrinol Metab 2003, 88(8):3993-3996.

26. Ding G, Fu M, Qin Q, Lewis W, Kim HW, Fukai T, Bacanamwo M, Chen YE Schneider MD, Mangelsdorf DJ, Evans RM, Yang Q: Cardiac peroxisome proliferator-activated receptor gamma is essential in protecting cardiomyocytes from oxidative damage. Cardiovasc Res 2007, 76(2):269-279.

27. Henderson BC, Sen U, Reynolds C, Moshal KS, Ovechkin A, Tyagi N, Kartha GK, Rodriguez WE, Tyagi SC: Reversal of systemic hypertension-associated cardiac remodeling in chronic pressure overload myocardium by ciglitazone. Int J Biol Sci 2007, 3(6):385-392.

28. Son NH, Park TS, Yamashita H, Yokoyama M, Huggins LA, Okajima K, Homma S, Szabolcs MJ, Huang LS, Goldberg IJ: Cardiomyocyte expression of PPARgamma leads to cardiac dysfunction in mice. J Clin Invest 2007, 117(10):2791-2801.

29. Krishnan J, Suter M, Windak R, Krebs T, Felley A, Montessuit C, TokarskaSchlattner M, Aasum E, Bogdanova A, Perriard E, Perriard JC, Larsen T, Pedrazzini T, Krek W: Activation of a HIF1alpha-PPARgamma axis underlies 
the integration of glycolytic and lipid anabolic pathways in pathologic cardiac hypertrophy. Cell Metab 2009, 9(6):512-524.

30. Lopaschuk GD, Ussher JR, Folmes CD, Jaswal JS, Stanley WC: Myocardial fatty acid metabolism in health and disease. Physiol Rev 2010, 90(1):207-258.

31. Smeets PJ, Teunissen BE, Willemsen PH, van Nieuwenhoven FA, Brouns AE, Janssen BJ, Cleutjens JP, Staels B, van der Vusse GJ, van Bilsen M: Cardiac hypertrophy is enhanced in PPAR alpha-/- mice in response to chronic pressure overload. Cardiovasc Res 2008, 78(1):79-89.

32. Arany Z, He H, Lin J, Hoyer K, Handschin C, Toka O, Ahmad F, Matsui T, Chin S, Wu PH, Rybkin II, Shelton JM, Manieri M, Cinti S, Schoen FJ, Bassel-Duby R, Rosenzweig A, Ingwall JS, Spiegelman BM: Transcriptional coactivator PGC-1 alpha controls the energy state and contractile function of cardiac muscle. Cell Metab 2005, 1(4):259-271.

33. He L, Kim T, Long Q, Liu J, Wang P, Zhou Y, Ding Y, Prasain J, Wood PA, Yang Q: Carnitine palmitoyltransferase-1b deficiency aggravates pressure overload-induced cardiac hypertrophy caused by lipotoxicity. Circulation 2012, 126(14):1705-1716

34. Grynberg A: Effectors of fatty acid oxidation reduction: promising new anti-ischaemic agents. Curr Pharm Des 2005, 11(4):489-509.

35. Cox KB, Liu J, Tian L, Barnes S, Yang Q, Wood PA: Cardiac hypertrophy in mice with long-chain acyl-CoA dehydrogenase or very long-chain acyl-CoA dehydrogenase deficiency. Lab Invest 2009, 89(12):1348-1354.

36. Sanderson LM, Boekschoten MV, Desvergne B, Muller M, Kersten S: Transcriptional profiling reveals divergent roles of PPARalpha and PPARbeta/delta in regulation of gene expression in mouse liver. Physiol Genomics 2010, 41(1):42-52.

37. Planavila A, Redondo I, Hondares E, Vinciguerra M, Munts C, Iglesias R, Gabrielli LA, Sitges M, Giralt M, van Bilsen M, Villarroya F: Fibroblast growth factor 21 protects against cardiac hypertrophy in mice. Nat Commun 2013, 4:2019.

doi:10.1186/1755-8794-7-35

Cite this article as: Verschuren et al: A systems biology approach to understand the pathophysiological mechanisms of cardiac pathological hypertrophy associated with rosiglitazone. BMC Medical Genomics 2014 7:35.

\section{Submit your next manuscript to BioMed Central and take full advantage of:}

- Convenient online submission

- Thorough peer review

- No space constraints or color figure charges

- Immediate publication on acceptance

- Inclusion in PubMed, CAS, Scopus and Google Scholar

- Research which is freely available for redistribution 